\title{
SeXual Selection of Male Song in Free-Living SAgebruSh CRICKETS, CYPHODERRIS STREPITANS
}

\author{
GEOFF D. OWER $\uparrow$ SANDRA STEIGER $\uparrow$ KYLE J. CARON $\uparrow$ SCOTT K. SAKALUK \\ SCHOOL OF BIOLOGICAL SCIENCES $\downarrow$ ILLINOIS STATE UNIVERSITY $\downarrow$ NORMAL, ILLINOIS
}

\begin{abstract}
$\uparrow \quad$ ABSTRACT
Measures of lifetime mating success in the sagebrush cricket, Cyphoderris strepitans, have revealed that most males succeed in obtaining only 1 mating, while many males fail to attract a female at all and a small minority mate 2 to 4 times. Relative to their abundance in the population, virgin males have a greater likelihood of obtaining a mating than nonvirgin males have of securing additional matings, a phenomenon known as the virgin male mating advantage. Previous studies of sagebrush crickets have focused primarily on determining the proximate mechanisms responsible for the virgin male mating advantage, but little work has been done to identify the factors that influence male attractiveness in the first place. Because song plays a central role in mate attraction, it's likely that variability in song parameters among males could account for the observed differences in mating success. Song is an energetically costly signal to produce and could serve as an honest indicator of male quality. Consequently, males that are able to invest greater amounts of energy into singing should be more attractive to females. In a previous field season, we recorded and analyzed the songs of virgin and non-virgin males and indeed found some evidence that females prefer males which invest greater energy into calling. In the present study, we synthesized artificial sagebrush cricket songs and directly measured female song preference with an arena playback experiment. Females were shown to consistently prefer song characteristics that would require greater energy expenditure by males. Males that sing with long pulse duration, long train duration, and at an intermediate dominant frequency were found to be highly attractive to females.
\end{abstract}

\section{$\downarrow \quad$ INTRODUCTION}

The sagebrush cricket, Cyphoderris strepitans, occurs in high-altitude sagebrush meadows and is one of seven known surviving species in the once highly diverse family Haglidae (Morris and Gwynne 1978, Kumala et al. 2005). Males emerge from their burrows at sunset and ascend the sagebrush where they sing late into the night, which functions as their primary means of attracting a female (Snedden \& Sakaluk 1992, Snedden \& Irazuzta 1994). Copulation is initiated when a female climbs onto the dorsum of a male. While the male attempts to transfer a spermatophore, the female feeds on the male's fleshy hind wings. This mating behavior makes the sagebrush cricket an ideal system for studies of sexual selection because it allows the mating status of males to be readily determined in the field by simply examining their hind wings for damage. Virgin males have pearlywhite hind wings, while the hind wings of nonvirgins are visibly wounded with melanized scars (Figure 1).

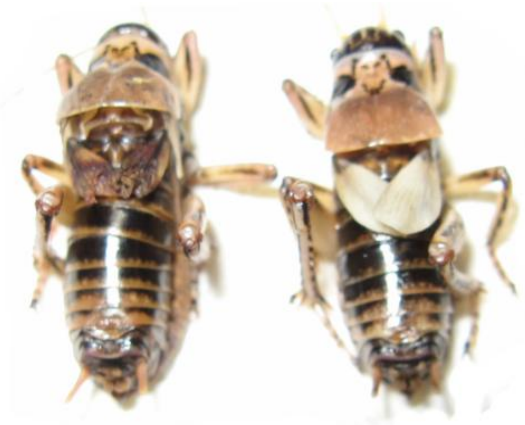

Figure 1. The hindwings of non-virgin males (left) are damaged by females during mating. Virgin males (right) have pearly-white, undamaged hindwings. Note: the forewings were removed. 


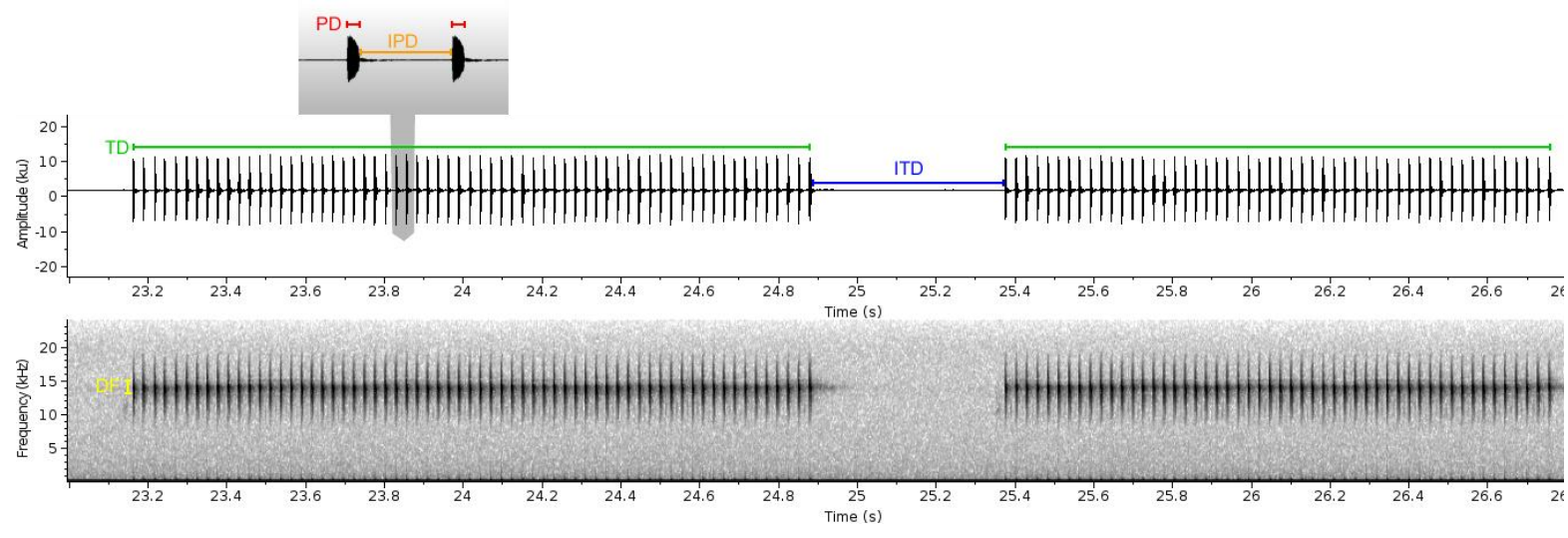

Figure 2. The five focal song characters: train duration (TD), pulse duration (PD), interpulse duration (IPD), intertrain duration (ITD), and dominant frequency (DF). Longer pulse and train duration are expected to increase energetic costs of singing, while longer interpulse and intertrain duration should decrease energy expenditure.

Relative to their abundance in the population, virgin males have a greater likelihood of obtaining a mating than non-virgin males have at securing additional matings - a phenomenon known as the virgin male mating advantage (Morris et al. 1989, Sakaluk and Ivy 1999). The reduced mating success of non-virgin males is a consequence of the wing wounds inflicted by females, which are accompanied by hemolymph loss (Sakaluk, et al. 2004) and an energetically costly immune response (Leman et al. 2009). Males that have recently mated have less energy available for singing and exhibit at least a short-term reduction in calling (Leman et al. 2009).

While previous studies on sagebrush crickets have focused on determining the proximate mechanism of the virgin male mating advantage, a more basic question has not been addressed: what factors influence male mating success in the first place? Measures of sagebrush cricket lifetime mating success have revealed that the median number of matings is 1 , with many males failing to attract a mate at all and a very small minority of males obtaining 2 to 4 matings (Morris et al. 1989). Because song is required for mate attraction (Snedden \& Sakaluk 1992), it likely plays a central role in determining mating success. The variable mating success of males could be explained by differences in song characteristics. Previous studies of acoustic Orthoptera have indeed shown that song features can influence male attractiveness (Bentsen, et al. 2006). What song characteristics, if any, influence attractiveness of sagebrush cricket males?

Acoustic signaling by Orthopterans is thought to impose high energetic costs on males (Prestwich \& Walker 1981, Hoback \& Wagner 1997,
Hack 1998, Bailey et al. 1993). Consequently, song may serve as an honest indicator of male quality (Zahavi 1975, Burk 1988). Males that are able to gain access to limited resources and efficiently convert those resources into attractive sexual signals are likely to be of superior quality and should have greater reproductive success (Holzer et al. 2003). Females may impose directional (linear) sexual selection on males by choosing mates that exhibit the greatest song-producing endurance. Additionally, females may also exert stabilizing (non-linear) selection on males if their auditory system is tuned to only a narrow range of sound frequencies. Males that produce song outside of this frequency range may fail to attract a female.

In a previous field season (Ower et al. 2009), we recorded the songs of virgin and non-virgin males and analyzed sexual selection on five focal song characters: pulse duration, interpulse duration, train duration, intertrain duration, and dominant frequency (Figure 2). Sagebrush crickets sing by stridulating their forewings together. During wing closure, the plectrum (analogous to a guitar pick) strikes the teeth on the file of the opposing wing. Each wing closure results in sound pulse, and multiple wing closures in quick succession produce a train of pulses (Figure 2). Singing with longer pulse duration requires the plectrum to remain in contact with the file longer, which should require a greater energy investment due to frictional resistance. In accordance with our expectations, males that sang with longer pulse durations (and greater energy investment), seemingly were more attractive because they had higher mating success (Ower et al. 2009). Contrary to our predictions, males that engaged in long bouts of energetic singing (long train durations or continual wing movement) apparently were 
unattractive because they tended to be virgins. This could be a result of the virgin male mating advantage: unmated males, having not incurred the costs of wing wounding, may have had greater resources to sustain long trains of song.

To determine which song characters are relevant to mate attraction it was necessary to conduct a second field experiment that directly measured female song preference in arena choice trials.

\section{METHODS}

The attractiveness of sagebrush cricket song was assessed by synthesizing artificial songs and conducting an arena playback experiment. Four arenas were setup at a field site neighboring the UWNPS research station. The UW-NPS research station has no nearby populations of sagebrush crickets, which gave us an acoustically controlled field environment for conducting audio playback choice trials. Aluminum flashing was placed around the arena perimeters $(2.0 \times 0.3 \times 0.1 \mathrm{~m})$ to contain the females. Speakers were positioned at the terminals of the arena at a height within the natural perching range of males singing in sagebrush meadows (Figure 3 ).

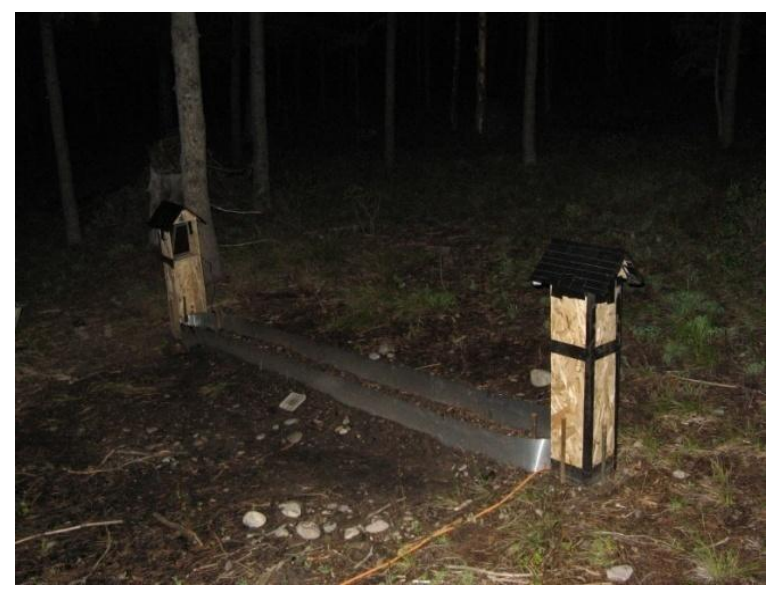

Figure 3. Females were placed in the middle of the choice trial arenas and the manipulated \& control signals were randomly assigned to the left or right speaker.
Female sagebrush crickets were captured from Deadman's Bar and were transported back to the UW-NPS research station, where they were placed into dirt-filled cages and provisioned with a diet of apple, bee pollen, and cat chow. On subsequent evenings, phonotaxis trials were conducted by placing a caged female at the center of an arena (Figure 3). Control and manipulated signals were broadcast from the left and right terminals of the arena. After 5 minutes of acclimation, the cage lid was very carefully removed, so as not to disturb the female. If a female approached within $0.3 \mathrm{~m}$ of the manipulated signal it was scored 1 for attractive or otherwise 0 for unattractive if the female preferred the control signal.

\section{Artificial Song Synthesis}

For each trial, the control and manipulated signal was randomly assigned to either the left or right speaker. The control was a composite signal, representing the mean trait values of each of the five focal song characters (Figure 2). The manipulated signals were generated by drawing an independent, random value from the known normalized distributions of each of the five focal song characters (Figure 2). This was advantageous, because it eliminated correlations between song characters that can make the selection analyses difficult to interpret. Random selection of each focal song character, independent of the others, also created songs that might be biophysically impossible for males to produce, allowing us to determine if female preference could drive sexual selection further than what might be naturally possible. Finally, it provided manipulative rather than descriptive evidence of sexual selection. All songs were artificially synthesized using Adobe Audition 3.

\section{Statistical Analysis}

The standard multiple regression method of selection analysis was used to estimate linear and nonlinear selection gradients for each of the five focal song characters (Lande \& Arnold 1983). Prior

Table 1. $\beta$ (linear) and $\gamma$ (nonlinear) coefficients from the multiple regression selection analysis. $\mathrm{p} \leq 0.05=*, \mathrm{p} \leq 0.01=* *, \mathrm{p} \leq 0.001$.

\begin{tabular}{lcccccc}
\hline & & \multicolumn{3}{c}{$\gamma$} \\
\cline { 3 - 6 } & $\boldsymbol{\beta}$ & $\mathbf{P D}$ & $\mathbf{I P D}$ & $\mathbf{D F}$ & $\mathbf{T D}$ & ITD \\
\hline Pulse Duration (PD) & -0.017 & 0.233 & & & & \\
InterPulse Duration (IPD) & 0.091 & -0.005 & -0.136 & & & \\
Dominant Frequency (DF) & 0.084 & 0.106 & -0.182 & $\mathbf{- 0 . 3 5 \%}$ & & \\
Train Duration (TD) & 0.159 & 0.078 & 0.057 & $\mathbf{0 . 2 5 7 *}$ & 0.104 & \\
InterTrain Duration (ITD) & -0.076 & -0.153 & -0.153 & -0.141 & -0.100 & 0.046 \\
\hline
\end{tabular}


a)

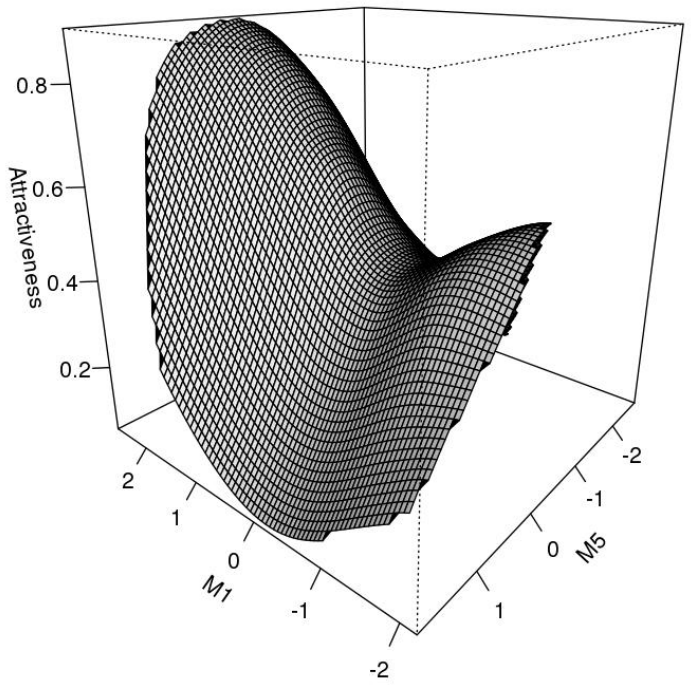

b)

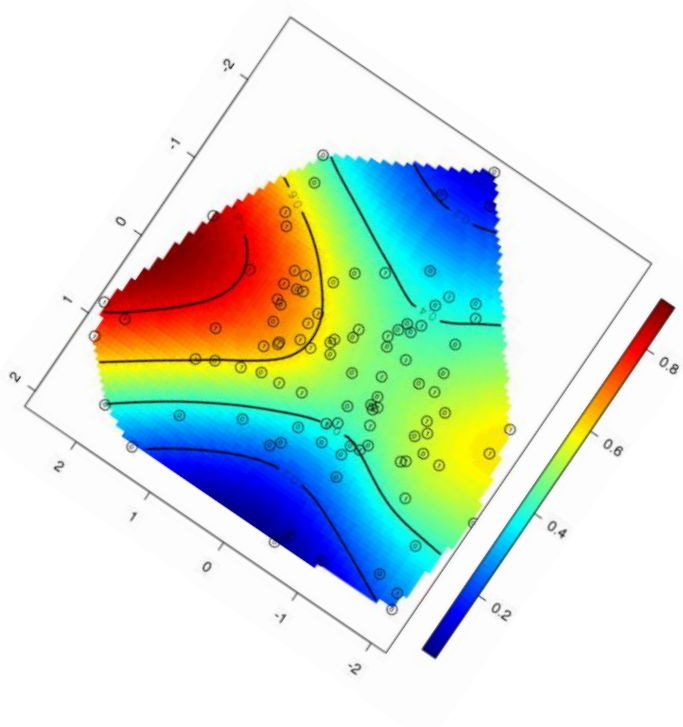

Figure 4. a) The thin-plate spline perspective view of the fitted surface between the significant M1 and M5 major axes. b) A contour map of the same fitness surface with each of the manipulated signal data points plotted. Songs located at higher elevations on the contour map were more attractive, while songs at lower elevations were less attractive.

to conducting the analysis, song characters were standardized to have a mean of 0 and standard deviation of 1 . Separate regression models were fit to estimate the vector of $\beta$ gradients (which represent linear selection) and matrix of $\gamma$ gradients (which represent both nonlinear and correlational selection). Because nonlinear selection is frequently underestimated due to the effects of correlational selection, canonical analysis was performed (Blows $\&$ Brooks 2003). Canonical analysis identifies the major axes of the fitness surface and rotates the data to eliminate correlations (Blows \& Brooks 2003). Regression models were fit to the rotated data, in which linear selection is represented by the $\theta$ gradients and nonlinear selection by the $\lambda$ gradients. To visualize the fitness surfaces, thin-plate splines were fitted to the data (Green \& Silverman 1994). All statistical analyses were done using the $\mathrm{R}$ statistical environment with the fields package ( $R$ Development Core Team 2011, Furrer, et al. 2011).

\section{$\downarrow \quad$ PRELIMINARY RESULTS}

Significant convex selection was found on dominant frequency (Table 1). There was also significant positive correlational selection between dominant frequency and train duration. None of the $\beta$ gradients, representing linear selection, were found to be significantly different from 0 (Table 1).

Canonical analysis rotated the data to eliminate correlations that can result in an underestimation of nonlinear selection. Two major axes (M1 \& M5) had significant nonlinear selection (Table 2). The $\lambda$ gradient for the M1 axis was positive, indicating a concave fitness surface. Pulse duration and train duration had the strongest influence along the M1 axis, with more minor contributions from dominant frequency and intertrain duration (Table 2). Along the M5 axis, the $\lambda$ gradient was very significantly negative, indicating a convex fitness surface (Table 2). Dominant frequency contributed very heavily to the M5 axis, with relatively minor contributions from interpulse duration, train duration, and intertrain duration.

The fitness surface that was fitted to the significant M1 and M5 major axes formed a saddle (Figure 4). The most attractive songs - found at the highest peak along the M1 axis-had larger M1 values and tended to have long pulse duration and long train duration (Figure 4). Along the M5 axis,

Table 2. $\theta$ (linear) and $\Lambda$ (nonlinear) coefficients from canonical analysis. $\mathrm{p} \leq 0.05=*, \mathrm{p} \leq 0.01=* *, \mathrm{p} \leq 0.001$.

\begin{tabular}{ccccccccc}
\hline & \multicolumn{9}{c}{ M } & & & & \multicolumn{2}{c}{ Selection } \\
\cline { 2 - 3 } \cline { 7 - 8 } & PD & IPD & DF & TD & ITD & & $\boldsymbol{\theta}$ & $\lambda$ \\
\hline M1 & $\mathbf{0 . 5 3 9}$ & 0.038 & 0.375 & $\mathbf{0 . 6 7 4}$ & -0.335 & & 0.159 & $\mathbf{0 . 1 8 1 *}$ \\
M2 & 0.693 & -0.265 & -0.033 & -0.205 & 0.637 & -0.120 & 0.134 \\
M3 & -0.461 & -0.566 & 0.288 & 0.451 & 0.426 & 0.020 & 0.011 \\
M4 & -0.088 & 0.649 & -0.329 & 0.464 & 0.497 & 0.069 & -0.060 \\
M5 & -0.093 & 0.433 & $\mathbf{0 . 8 1 7}$ & -0.291 & 0.230 & -0.046 & $\mathbf{- 0 . 2 9 9} * * *$ \\
\hline
\end{tabular}


songs with intermediate dominant frequency - or M5 values that were closer to zero-were more attractive, while songs with very low or high dominant frequency were highly unattractive (Figure 4).

Males that sing at a dominant frequency deviating significantly from the population mean of 12.7 $\mathrm{kHz}$ have a much lower likelihood of successfully attracting a mate. The female auditory system is perhaps tuned to a narrow frequency range, which would impose stabilizing selection on dominant frequency. Males that sing outside of the hearing range of females presumably would not succeed in attracting a mate and would have a fitness value of 0 .

Females preferred songs with long pulse duration and long train duration, and producing these signals would demand greater energy expenditure by males. Non-virgin males are at a competitive disadvantage, due to the damage inflicted by the hindwing feeding behavior of females during copulation. In addition to having lost hemolymph, the wounds on their hindwings may become infected, requiring a costly immune system response that would consume energy which might otherwise have been available for singing to attract another mate (Leman, et al. 2009).

The virgin male mating advantage explains why males that sung in long, energetic bouts of song (long train duration) were counterintuitively found to be unattractive in our previous field experiment (Ower, et al. 2009). Virgin males can afford to invest more energy into calling. The virgin males that sung with long train duration likely would have obtained at least one mating later in the field season.

Non-virgin males that are able to obtain additional matings could be more proficient in converting resources into song through a more efficient metabolic system, superior calling musculature, or a better song producing apparatus. They could, perhaps, also have superior immune systems. More research is needed to determine which factors allow a relatively small number of non-virgin males to obtain multiple matings, when they are at a competitive disadvantage with virgin males.

\section{ACKNOWLEDGEMENTS}

Due to challenging field conditions from a very late spring followed by heavy, frequent rainstorms, we could not have captured enough female sagebrush crickets without the help of Chuck
Collis, Katie Storms and their students Alex Breckenridge, Tanner Fortune, Lily Gage, and Sarah McAfee from Clayton High School in St. Louis, MO. We'd like to thank the University of Wyoming and National Park Service for accommodating us with such a wonderful research station. Funding for this project was provided by the National Science Foundation and the Beta Lambda Chapter of the Phi Sigma Biological Honors Society.

\section{LITERATURE CITED}

Bailey WJ, Withers PC, Endersby M, Gaull K. 1993. The energetic costs of calling in the bushcricket Requena verticalis (Orthoptera: Tettigoniidae: Listroscelidinae). Journal of Experimental Biology 178: 21-37.

Bentsen C, Hunt J, Jennions MD, Brooks R. Complex multivariate sexual selection on male acoustic signaling in a wild population of Teleogryllus commodus. American Naturalist 167: E102-E116.

Blows MW, Brooks R. 2003. Measuring nonlinear selection. American Naturalist 162: 815820.

Burk T. 1988. Acoustic signals, arms races and the costs of honest signaling. The Florida Entomologist 71: 400-409.

Furrer R, Nychka D, Sain S, Nychka D (maintainer). 2011. Fields: Tools for spatial data. http://cran.r-

project.org/web/packages/fields/index.html

Green, PG, Silverman BW. 1994. Nonparametric regression and generalized linear models. Boca Ration, FL: CRC Press, LLC.

Hack, MA. 1998. The energetics of male mating strategies in field crickets (Orthoptera: Gryllinae: Gryllidae). Journal of Insect Behavior 11: 853-867.

Hoback WW, Wagner WE. 1997. The energetic cost of calling in the variable field cricket, Gryllus lineaticeps. Physiological Entomology 22: 286-290.

Holzer B, Jacot A, Brinkhof MWG. 2003. Conditiondependent signaling affects male sexual attractiveness in field crickets, Gryllus campestris. Behavioral Ecology 14: 353-359. 
Kumala M, McLennan DA, Brooks DR, Mason AC. 2005. Phylogenetic relationships within Hump-Winged Grigs, Cyphoderris (Insecta, Orthoptera, Tettigonioidea, Haglidae). Canadian Journal of Zoology 83: 10031011.

Lande R, Arnold SJ. 1983. The measurement of selection on correlated characters. Evolution 37: 1210-1226.

Leman JC, Weddle CB, Gershman SN, Kerr AM, Ower GD, St John JM, Vogel LA, Sakaluk SK. 2009. Lovesick: immunological costs of mating to male sagebrush crickets. Journal of Evolutionary Biology 22: 163-171.

Morris GK, Gwynne DT. 1978. Geographic distribution and biological observations of Cyphoderris (Orthoptera: Haglidae) with a description of a new species. Psyche 85: 147-167.

Morris GK, Gwynne DT, Klimas DE, Sakaluk SK. 1989. Virgin-male mating advantage in a primitive acoustic insect (Orthoptera: Haglidae). Journal of Insect Behavior 2: 173-185.

Ower GD, Smith RA, Caron KJ, Sakaluk SK. 2009. When love comes calling: measuring sexual selection on sagebrush crickets. University of Wyoming-National Park Service Report.

Prestwich KN, Walker TJ. 1981. Energetics of singing in cricket: effect of temperature in three trilling species (Orthoptera: Gryllidae). Journal of Comparative Physiology 143: 199-212.
R Development Core Team. 2011. R: A language and environment for statistical computing. http://www.r-project.org

Sakaluk SK, Campbell MTH, Clark AP, Johnson JC, Keorpes PA. 2004. Hemolymph loss during nuptial feeding constrains male mating success in sagebrush crickets. Behavioral Ecology 15: 845-849.

Sakaluk SK, Ivy TM. 1999. Virgin-male mating advantage in sagebrush crickets: differential male competitiveness or non-independent female mate choice? Behaviour 10: 13351346.

Snedden WA, Irazuzta S. 1994. Attraction of female sagebrush crickets to male song: the importance of field bioassays. Journal of Insect Behavior 7: 233-236.

Snedden WA, Sakaluk WA. 1992. Acoustic signaling and its relation to male mating success in sagebrush crickets. Animal Behaviour 44:633-639.

Zahavi A. 1975. Mate selection-a selection for a handicap. Journal of Theoretical Biology 53: 205-214. 